\title{
МОДЕЛИ КОМПЕТЕНЦИЙ РУКОВОДИТЕЛЕЙ ИННОВАЦИОННЫХ ПРОЕКТОВ И ВОЗМОЖНОСТИ ИХ ИСПОЛЬЗОВАНИЯ НА ПРОМЫШЛЕННЫХ ПРЕДПРИЯТИЯХ
}

\author{
(c) 2019 Бурмистров Андрей Николаевич \\ кандидат экономических наук, доцент Высшей школы сервиса и торговли \\ Санкт-Петербургский политехнический университет Петра Великого, Россия, Санкт-Петербург \\ E-mail: isar@mail.ru
}

(c) 2019 Синявина Мария Павловна

ст. преподаватель Высшей школы сервиса и торговли

Санкт-Петербургский политехнический университет Петра Великого, Россия, Санкт-Петербург E-mail:sinmp@inbox.ru

(c) 2019 Рассказова Ольга Анатольевна

кандидат экономических наук, доцент Высшей школы сервиса и торговли Санкт-Петербургский политехнический университет Петра Великого, Россия, Санкт-Петербург E-mail: olanka777@yandex.ru

(C) 2019 Александров Игорь Николаевич

кандидат экономических наук, доцент Высшей школы сервиса и торговли Санкт-Петербургский политехнический университет Петра Великого, Россия, Санкт-Петербург E-mail: a7830298@gmail.com

Проведено исследование моделей компетенций руководителей проектов, представленных в современной научной литературе и нормативных документах по проектному управлению. Разработана классификация таких моделей. Выявлены существенные ограничения возможности их применения для целей управления инновационными проектами на промышленных предприятиях, связанные с их высокой сложностью. Обоснована необходимость разработки специальных, более простых моделей, предназначенных для малых и средних предприятий, а также для проектов относительно небольшого масштаба, осуществляемых на крупных промышленных предприятиях.

Ключевые слова: проект, инновационный проект, модель компетенций, руководитель проекта, управление проектом

Актуальность. В настоящее время во всем мире, в том числе и в нашей стране, возрастает роль инновационной деятельности. Во все большем количестве предприятий осуществляются самые разнообразные инновационные проекты. Это, главным образом, продуктовые инновации: например, проектирование и производство новой продукции с заданными свойствами (как на заказ, так и для рынка).

На многих предприятиях, в том числе на малых и средних промышленных предприятиях, которые осуществляют продуктовые инновации (в частности, проектирование и производство отдельных компонентов новой продукции при позаказном производстве), а также для выполнения других инновационных проектов необхо- димы руководители проектов. Назначение этих руководителей происходит, как правило, субъективно (без использования формализованных методов). В результате во многих случаях характеристики руководителей проектов не соответствуют специфике этих проектов, что приводит к сложностям управления проектами и недостаточной их эффективности.

Причины, по которым формализованные методы назначения руководителей проектов не используются, различны. Одной из них является сложность создания и использования моделей, используемых при оценке компетенций руководителей. В исследовании рассматриваются возможности использования моделей оценки компетенций, представленных в научной и ме- 
тодической литературе, применительно к промышленным предприятиям. Внимание именно к промышленным предприятиям обусловлено тем, что продукция предприятий промышленности (главным образом, обрабатывающей промышленности) является относительно более сложной, чем продукция предприятий других отраслей (разработки программного обеспечения, транспорта, сферы услуг и т.д.), поэтому к руководителям проектов предъявляются более высокие требования, чем для предприятий других отраслей.

Методы. В работе были изучены модели, предназначенные для повышения качества управления проектами, представленные в научной и методической литературе, главным образом в международных и отечественных стандартах. В связи с тем, что к инновационным проектам применимы те же модели, что и к управлению проектами вообще (см., например, [1]), это представляется оправданным, так как любой проект по определению содержит определенную долю инновационости.

Обзор литературы. Вопросам повышения качества управления посвящено большое количество публикаций, которые можно разделить на следующие основные группы: об управлении проектами в целом, о командах проектов и об отдельных участниках проектных команд, в том числе о руководителях проектов.

Об управлении проектами в целом существует обширная литература, а также несколько международных и отечественных стандартов по управлению проектами, в частности, ГОСТ Р 54869-2011 [2], ГОСТ Р ИСО 21500-2014 [3], стандарты PMBoК, OMP3 и др. Института управления проектами США (РМI), национальные стандарты PRINCE2 (Великобритания), Р2M (Япония), моделям оценки зрелости проектного управления и т.д. см., например, обзоры в [4], [5] и другие, рассмотрение вопросов управления проектами не входит в задачи данного исследования и ниже будут представлены только те стандарты, которые необходимы для понимания модели компетенций руководителей проектов.

Вопросам создания инновационных команд посвящено большое количество публикаций, в которых представлен ряд моделей. Например, это модель GRPI Рубина, Пловника и Фрая (1977), модель эффективности Д. Катценбаха и Д. Смита (1993), модель 7Т М. Ломбардо и Р. Эйчинге- ра (1995), модель Ф. ЛаФасто и К. Ларсона (2001), модель Дж.Р. Хэкмана (2002), модель П. Ленциони (2005) и другие (см., например, [6]). Их рассмотрение не входит в данное исследование.

Наиболее подробно мы рассмотрим вопросы оценке компетенций руководителей проектов. Эталонные модели компетенций для руководителей проектов представлены в нескольких международных и отечественных стандартах, в частности, в стандартах GPBSPMP и разработанным на его основе ГОСТ Р 52807-2007 и ГОСТ Р 53892-2010, ICB (IPMA), PMCD Framework (PMI). Иногда эти вопросы рассматриваются совместно с более общими вопросами формирования команд проектов и управления проектами в целом (см., например, [7], [8]).

Для оценки характеристик участников проектных команд, как и для оценки руководителей проектов (и других работников организаций), доминирует в настоящее время компетентностный подход. Считается, что впервые понятие «компетенция» было сформулировано Дэвидом Мак-Клелландом. Они понимал под «компетенциями» то поведение, которое отличает выдающегося работника от среднего [9]. Обобщая определения понятия «компетенция», приведенные в многочисленных научных и популярных публикациях (см., например, [10], можно сказать, что «компетенция» - совокупность умений, знаний и личностных качеств, которые необходимы, чтобы добиваться заданных результатов при выполнении определенной работы. Для использования компетентностного подхода используются многочисленные модели компетенций. Модель компетенций - система требований к работнику, основанная на полном определении работы или работ в терминах поведения [11].

Результаты. Классификация моделей, которые можно использовать для оценки компетенций руководителей проектов, представлена в Таблице 1. Рассмотрим отдельные классы моделей и их содержание.

1 Модели управления проектами, представленные в стандартах по управлению проектами

В наиболее общем виде категории компетенций в области проектного менеджмента представлены в стандартах по управлению проектами, например, в ГОСТ Р ИСО 21500-2014:

- технические компетенции - технические знания и навыки, позволяющие осуществлять 
Таблица 1. Классификация моделей компетенций руководителей проектов

\begin{tabular}{|c|c|c|}
\hline $\begin{array}{c}\text { Уровень общности модели } \\
\text { Объект рассмотрения }\end{array}$ & $\begin{array}{c}\text { Обобщенные модели } \\
\text { (для всех предприятий) }\end{array}$ & $\begin{array}{c}\text { Конкретные модели } \\
\text { (для отдельных предприятий) }\end{array}$ \\
\hline $\begin{array}{l}\text { Модели управления проектами, } \\
\text { включающие модели компетенций } \\
\text { руководителей проектов }\end{array}$ & $\begin{array}{l}\text { ИСО 21500, } \\
\text { ГОСТ Р 54869-2011, } \\
\text { РМВоК, ОМР3 и др. Института } \\
\text { управления проектами США (РMI), } \\
\text { национальные стандарты РRINCE2 } \\
\text { (Великобритания), Р2М (Япония) и } \\
\text { другие. }\end{array}$ & $\begin{array}{l}\text { Как правило, являются конфиден- } \\
\text { циальной информацией. В доступ- } \\
\text { ных публикациях представлены } \\
\text { только модели управления проек- } \\
\text { тами, например, [12] }\end{array}$ \\
\hline $\begin{array}{l}\text { Модели компетенций руководите- } \\
\text { лей проектов }\end{array}$ & $\begin{array}{l}\text { GPBSPMP и разработанным на его } \\
\text { основе ГОСТ Р 52807-2007 и ГОСТ } \\
\text { P 53892-2010, } \\
\text { ICB (IPMA), } \\
\text { PMCD Framework (PMI). } \\
\text { Профессиональные стандарты (РФ) }\end{array}$ & $\begin{array}{l}\text { Как правило, являются конфиден- } \\
\text { циальной информацией. Неко- } \\
\text { торые модели представлены в } \\
\text { разделе «Модели компетенций для } \\
\text { российских предприятий» }\end{array}$ \\
\hline
\end{tabular}

системное управление проектом, в том числе знания о терминологии, принципах и процессах проектного менеджмента, приведенные в стандарте;

Примечание 1 (авторов): В стандарте определены 5 управленческих групп процессов проектного менеджмента (инициирование, планирование, исполнение, контроль, завершение) и 10 предметных групп:

- Интеграция

- Содержание

- Сроки

- Риски

- Закупки

- Заинтересованные стороны

- Ресурсы

- Стоимость

- Качество

- Коммуникации

- поведенческие компетенции, определяющие способность руководителя строить отношения с участниками проекта;

- контекстные компетенции, связанные с управлением проектом в рамках определенной организационной среды и внешнего окружения.

Примерно такие же общие рекомендации представлены также в стандартах PRINCE2 и P2M. Национальный стандарт Великобритании по управлению проектами Project In Controlled Environment (PRINCE2), разработанный Тhe Office of Government Commerce (OGC), Великобритания. Компетенции роли «руководитель проекта» по PRINCE2:

\footnotetext{
- Стратегия
}

- Линейный менеджмент

- Управление стоимостью

- Коммуникации

- Качество

- Статус продукта

- Продукт и потребности проекта

- Изменения

- Потребности пользователей

- Мониторинг

- Планирование

- Командная работа [13]

Национальный стандарт Японии по управлению проектами и программами The Guidebook for Project and Program Management for Enterprise Innovation (P2M), разработанный Project Management Association of Japan (РМAJ) Ассоциация по управлению проектами Японии. Модель компетенций в Р2М состоит из 10 элементов:

- Целостное мышление;

- Стратегическое мышление;

- Интегральное мышление;

- Лидерство;

- Способность планирования (компетенция планирования);

- Способность выполнения (компетенция выполнения);

- Координация;

- Навыки взаимоотношений;

- Нацеленность на достижение результата;

- Самореализация [14].

(Примечание 2. Наиболее простую структуру из стандартов управления проектами имеет отечественный стандарт ГОСТ Р 54869-2011, но понятие «компетенции» в нем не используется.) 
2 Модели компетенций руководителей проектов, представленные в стандартах

Согласно стандарту Project manager competency development framework (PMCD Framework) Американского института управления проектами PMI, компетенции руководителя проекта имеют следующую структуру ([15], о русском издании см. [16]):

Знания по управлению проектами (соответствуют 9 областям проектного управления по PMBoK):

- Управление интеграцией проекта;

- Управление сроками проекта;

- Управление качеством проекта;

- Управление коммуникациями проекта;

- Управление поставками проекта;

- Управление содержанием проекта;

- Управление стоимостью проекта;

- Управление человеческими ресурсами проекта;

- Управление рисками проекта;

- Управление стэйкхолдерами (заинтересованными сторонами).

Практика применения знаний (по 5 группам процессов выполнения проекта):

- Процессы инициирования проекта

- Процессы исполнения проекта

- Процессы закрытия проекта

- Процессы планирования проекта

- Процессы мониторинга и контроля проекта

Персональные компетенции (поведенческие и контекстуальные, 6 областей):

- Коммуникационные

- Менеджмент

- Результативность (эффективность)

- Лидерство

- Познавательные способности

- Профессионализм

ГОСТ P 52807-2007 [17] и ГОСТ Р 538922010 [18] (аналогичны GPBSPMP [19]). В ГОСТ Р 52807-2007 выделено 7 областей компетенций:

OK 1. Управление отношениями между участниками проекта.

OK 2. Управление межличностными отношениями.

OK 3. Управление разработкой плана проекта.

OK 4. Управление процессом выполнения проекта.

OK 5. Управление приемкой продукции.

ОК 6. Управление переходами между фазами проекта.

ОК 7. Оценка и улучшение результативности проекта.

Стандарт «International Competence Baseline» (ICB), разработанный International Project Management Association (IPMA) [20]. В IPMA используется модель 4-LC - Four Level Certification, которая используется для сертификации специалистов на уровни: А. Директор проектов, В. Управляющий проектом, С. Профессионал по управлению проектами, D. Специалист по управлению проектами. В ICB представлено три группы элементов компетентности:

1. Технические компетенции (20 элементов):

1.01 Успех управления проектом; 1.02 Заинтересованные стороны; 1.03 Требования и задачи проекта; 1.04 Риск и возможность; 1.05 Качество; 1.06 Организация проекта; 1.07 Командная работа; 1.08 Разрешение проблем; 1.09 Структуры проекта; 1.10 Замысел и результаты; 1.11 Время и фазы проекта; 1.12 Ресурсы; 1.13 Затраты и финансы; 1.14 Снабжение и договорная деятельность; 1.15 Изменения; 1.16 Контроль и отчетность; 1.17 Информация и документирование; 1.18 Коммуникации; 1.19 Начало проекта; 1.20 Завершение.

2. Поведенческие компетенции (15 элементов):

2.01 Лидерство; 2.02 Обязательства; $2.03 \mathrm{Ca}$ моконтроль; 2.04 Убедительность; 2.05 Расслабленность; 2.06 Открытость; 2.07 Креативность; 2.08 Ориентированность на результат; 2.09 Эффективность; 2.10 Консультации; 2.11 Переговоры; 2.12 Конфликты и кризисы; 2.13 Надежность; 2.14 Внимание к ценностям; 2.15 Этика.

3. Контекстуальные компетенции (11 элементов):

3.01 Ориентация проекта; 3.02 Ориентация программы; 3.03 Ориентация портфеля; $3.04 \mathrm{Pe}-$ ализация проекта, программы и портфеля; 3.05 Постоянная организация; 3.06 Бизнес; 3.07 Системы, продукты и технология; 3.08 Управление персоналом; 3.09 Охрана труда и окружающей среды; 3.10 Финансы; 3.11 Юридические вопросы [21].

Российская ассоциация управления проектами COBНЕТ на основе указанного стандарта ICB v.3 разработала документ Управление проектами: Основы профессиональных знаний, $\mathrm{Ha}^{-}$ циональные требования к компетентности специалистов (НTK) [22] 
Объекты управления и контекстуальная компетентность

1. Проект

2. Программа

3. Портфель проектов и программ

4. Проектно-ориентированная организация

5. Системы, продукты, технологии

6. Требования, цели и стратегия проекта

7. Критерии успешности проекта

8. Структуры проекта

9. Фазы и жизненный цикл проекта

10. Окружение проекта и деловая активность организации

Субъекты управления и поведенческая компетентность

11. Заинтересованные стороны проекта

12. Постоянная (родительская) организация

13. Команды проекта

14. Организационная структура проекта

15. Руководство и лидерство

16. Вовлеченность и мотивация

17. Самоконтроль

18. Уверенность и убедительность

19. Снятие напряженности

20. Открытость

21. Творческий подход

22. Ориентированность на результат

23. Эффективность

24. Согласование

25. Переговоры

26. Конфликты и кризисы

27. Надежность

28. Понимание ценностей

29. Этика

30. Разрешение проблем

31. Информация и документы

32. Стандарты

33. Правовое обеспечение проектной деятельности

34. Особенности проектного управления с позиций различных заинтересованных сторон

Процессы управления и техническая компетентность

35. Проектно-ориентированное управление

36. Внедрение проектного управления

37. Инициация проекта

38. Планирование проекта

39. Организация и контроль выполнения проекта

40. Анализ и регулирование выполнения проекта

41. Закрытие проекта
42. Управление предметной областью проекта

43. Управление проектом по временным параметрам

44. Управление стоимостью и финансированием проекта

45. Управление качеством в проекте

46. Управление рисками и возможностями в проекте

47. Управление человеческими ресурсами в проекте

48. Управление коммуникациями в проекте

49. Управление закупками и контрактами в проекте

50. Управление изменениями в проекте

51. Управление безопасностью в проекте

Общая компетентность

52. Системная методология управления проектами

53. Организационно-технологическая зрелость компании в области управления проектами

54. История и тенденции развития управления проектами

55. Особенности управления проектами в условиях кризиса

3 Профессиональные стандарты (РФ)

В «СОВНЕТ» был разработан «Проект профессионального стандарта «Руководитель проектов», включающий описание обобщенных трудовых функций, соответствующих «Управленческим группам процессов» (5 групп), трудовых функций, соответствующих «Предметным группам» из ИСО 21500 [23], и характеристик этих функций, включающих описание трудовых действий, необходимых умений и знаний, а также другие характеристики [24].

Примечание 3. Министерством труда и социальной защиты РФ принят также профессиональный стандарт «Руководитель проектов в области информационных технологий» [25].

Примечание 4. О других стандартах по компетенциям руководителей проектов, в которых изложены близкие модели, например:

CPPP - Certified Project Practitioner / CPPM - Certified Practicing Project Manager / CPPD - Certified Practicing Project Director $\mathrm{AB}^{-}$ стралийского института управления проектами AIPM; Международная инициатива GAPPS: Performance Based Competency Standards for Program Managers; The APM Competence 
Framework (2008), основанный на APM Body of Knowledge Ассоциации по управлению проектами Великобритании (Association for Project Management- APM); а также об основных международных и национальных стандартах по управлению проектами см., например, в [26] и в [27].

Мы согласны с тем, что при всей своей полезности «стандарты не содержат информацию о том, как разработать сбалансированную модель компетенций специалистов, участвующих в проектной деятельности организации, учесть специфику этой деятельности и отразить ее в модели, они лишь обобщают лучшие практики в области компетенций» [28].

\section{4 Модели компетенций для российских предприятий}

Разнообразные модели компетенций содержатся и в научной литературе, среди которых есть и модели компетенций руководителей проектов. Например, О. Клименко в работе [29], выполненной в крупном российском холдинге, оперирующем на пяти рынках и имеющем разнонаправленные бизнесы, приводит следующий набор компетенций для позиции «руководитель проекта» по трем наиболее важным составляющим: личностные качества, профессиональные и общие знания, умения, навыки. Полученная карта ключевых компетенций:

1. Личностные качества

- Готовность взять на себя ответственность

- Инициативность, высокая энергетика, способность к мотивации людей

- Системное мышление

- Коммуникабельность, способность поддерживать контакт, способность чувствовать людей

- Креативность, харизма, самоконтроль

- Честность

- Гибкость

2. Профессиональные знания

- Базовое образование должно быть экономическое/техническое или управленческое, а еще лучше - и то, и другое

- Опыт в области успешной реализации проектов обязателен

- В зависимости от сложности/масштабов проекта, рекомендуемый опыт должен быть в диапазоне от двух до десяти лет

3. Общие знания, умения, навыки

- Способность к созданию команд, распределению ресурсов
- Способность «вычленить ядро мысли» каждого члена команды

- Знания в области финансового анализа проектной деятельности

- Навык разработки и исполнения проектов

- Основы коммерческого права

- Обучаемость

- Навыки презентации и переговоров

- Знание бухгалтерии, принципов экономики

- Знания в области программных продуктов

- Навыки и знания в области управления персоналом

Личностные установки, играющие важную роль при назначении сотрудника на роль руководителя проекта:

1. лидерство;

2. терпение;

3. целеустремленность;

4. умение слушать;

5. самостоятельность;

6. исполнительность;

7. самодисциплина.

Заметим, что данная модель не вполне соответствует структуре международных и отечественных стандартов и создана для конкретной крупной организации. Большинство авторов постулируют необходимость разработки модели компетенций руководителей для каждого конкретного случая, то есть релевантной конкретной организации. Эти модели являются довольно сложными (см., например, обзор в [30]) и базируются главным образом на основополагающей работе Л. Спенсер и С. Спенсер [31]. В ней предлагается для каждой должностной позиции использовать два возможных способа:

Проектирование классического исследования при помощи критериальных выборок. Проводится в несколько этапов:

1. Определение критериев эффективности исполнения.

2. Определение критериальной выборки.

3. Сбор данных.

4. Анализ данных и разработка модели компетенций.

5. Валидизация модели компетенций.

6. Подготовка приложений модели компетенций.

Краткий процесс построения модели компетенций, основанный на группах экспертов. Состоит из меньшего количества этапов:

1. Сбор групп экспертов 
2. Проведение интервью по получению поведенческих примеров (дополнительный этап)

3. Анализ данных и разработка модели компетенций

4. Валидизация модели компетенций

В обоих случаях на этапе валидизации модели компетенций* требуется наличие контрольной группы сотрудников (а лучше двух).

Близкой технологии придерживаются и отечественные авторы [32], причем они выделяют для одной должности около 10 подкатегорий задач, для каждой из подкатегории около 10 необходимых умений и навыков, на основе которых выявляются несколько компетенций. В данной статье [33] авторами выделяются следующие блоки компетенций: «Профессиональная компетентность», «Управленческая компетентность», «Работа с информацией», «Коммуникативная компетентность», «Личностный блок». В каждом блоке перечисляются компетенции, входящие в него и расшифровывается их содержание.

В примере, рассмотренном авторами, для отдела работы с кадрами они выделили 7 «групп компетентностей»: «Техническая осведомленность», «Стратегичность», «Организация работы и контроль», «Аналитичность и системность мышления», «Убедительность», «Внимательность», «Стрессоустойчивость». Представляется, что для рассматриваемых нами инновационных проектов (более сложных, чем работа в отделе кадров), по указанной авторами методике было бы выделено не меньше, а скорее всего, больше «групп компетентностей».

Из представленных выше сведений видно, что разработка системы требований к поведению работников (модели компетенций), а также проверка работников на соответствие ей является весьма сложным и трудоемким процессом. Как указывают специалисты в данной области, «Разработка простой модели компетенций занимает довольно много времени. Это примерно от 2 до 4 месяцев.» [34]

Таким образом, при проведении исследования было установлено следующее:

1. В научной и методической литературе представлены различные модели компетенций руководителей проектов, в которых используется, компетентностный подход и которые могут использоваться для комплексной оценки компетентности потенциальных руководителей про- ектов и принятии решения о назначении руководителя проектов на основании объективных критериев. Ядром всех моделей являются компетенции, позволяющие осуществлять системное управление проектами.

2. Модели системного управления проектами, представленные, в частности, в международном стандарте ИСО 21500 (ГОСТ Р ИСО 21500-2014), а также в стандартах РМВоК (США), PRINCE2 (Великобритания), Р2М (Япония), ГОСТ P 54869-2011 (РФ), имеют очень много общего, но также имеют и отличия, то есть не являются идентичными.

3. Из моделей системного управления проектами наиболее простой является модель, представленная в отечественном ГОСТ Р 548692011, однако этот стандарт не содержит перечня компетенций в явном виде и в случае его использования должен применяться совместно с ГОСТ Р 52807-2007 и ГОСТ Р 53892-2010.

4. Модели компетенций, разработанные для руководителей проектов на российских предприятиях, существенно отличаются от моделей, представленных как в международных, так и в отечественных стандартах.

5. Для всех моделей наряду с комплексностью характерна высокая сложность. Поэтому разработка модели компетенций для руководителей инновационных проектов на их основе трудоемка, длительна и требует привлечения высококвалифицированных специалистов и т.д.

6. Модели компетенций руководителей проектов являются обобщенными (универсальными) и рассчитаны на проекты высокой сложности. То есть их применение требует условий, соблюдение которых возможно, как правило, только на крупных предприятиях.

7. В моделях компетенций руководителей проектов не применяются и даже не упоминаются гибкие (Agile) методологии, которые получают всё большее распространение не только при разработке программных продуктов, но и в других областях деятельности.

Использование результатов. Учитывая разнообразие имеющихся эталонных моделей оценки компетенций руководителей проектов, а также различный уровень развития проектного управления на российских предприятиях, целесообразно сформулировать следующие рекомендации:

\footnotetext{
* Валидизация - проверка обоснованности и пригодности методики, полученной в результате исследования в конкретных условиях
} 
- Для малых и средних предприятий целесообразно не разрабатывать модели компетенций для себя «с нуля», а адаптировать «под себя» эталонные модели, представленные в научной и методической литературе.

- Чем менее развито проектное управление на предприятии, тем с более простых эталонных моделей следует начинать создание формализованной системы проектного управления, в частности, в части применения систем компетенций и формализованных методов оценки компетентности руководителей проектов. В этом случае можно рекомендовать начинать с модели системного управления проектами, изложенной в стандарте с наиболее простой структурой ГОСТ Р 54869-2011 «Проектный менеджмент. Требования к управлению проектом» и адаптации ГОСТ Р 52807-2007. «Руководство по оценке компетентности менеджеров проектов», имеющий «всего» семь областей компетенций.

- По мере освоения методов проектного управления можно переходить к более сложным моделям. В части системного управления проектами целесообразно использовать международный стандарт ИСО 21500 (ГОСТ Р ИСО 215002014 Руководство по проектному менеджменту), а в части модели компетенций - проект проф. стандарта «Руководитель проектов» (разрабо- танный СОВНЕТ) который рано или поздно будет принят официально.

- Использовать более сложные стандарты только в случае необходимости получения международных сертификатов, например, для допуска к конкурсным закупкам, осуществляемых крупными компаниями.

Выводы. Рассмотренные эталонные модели компетенций руководителей проектов предназначены для крупных предприятий и крупных и сложных проектов. Они не предназначены для многочисленных «малых и средних» инновационных проектов, связанных, например, с осуществлением организационных и маркетинговых инноваций в рамках непрерывного улучшения деятельности промышленных предприятий. Эти модели также не предназначены для малых и средних производственных предприятий из-за высокой сложности применения указанных моделей.

В связи с этим перспективным направлением дальнейших исследований представляется разработка специальных, более простых моделей, предназначенных, главным образом, для малых и средних предприятий, а также для проектов относительно небольшого масштаба, осуществляемых на крупных предприятиях, особенно промышленных.

\section{Библиографический список}

1. Сорокин А. Компетенции участников проектного управления инновационной деятельностью // Наука и инновации. - 2017. - № 2 (168). - С. 40-43.

2. ГОСТ Р 54869-2011 Проектный менеджмент. Требования к управлению проектом. Национальный стандарт РФ.-М.: Стандартинформ, 2012.-12с.;

3. ГОСТ Р ИСО 21500-2014 Руководство по проектному менеджменту. Национальный стандарт РФ.- М.: Стандартинформ, 2015.- 52с.;

4. Дегтярев М.А. Международные и национальные стандарты управления проектами // Промышленный электрообогрев и электроотопление. - 2014. - № 3.- С. 54-64

5. Николаенко В.С., Мирошниченко Е.А., Грицаев Р.Т. Модели зрелости управления проектами: критический обзор [электронный ресурс] // Государственное управление. Электронный вестник. Выпуск № 73. Апрель 2019 г. С. 71-111._- URL.: http://e-journal.spa.msu.ru/vestnik/item/73_2019nikolaenko_miroshnichenko_grisaev. htm (дата обращения: 26.05.2019)

6. Lionel Valdellon. Шесть различных моделей эффективности командной работы [Электронный ресурс]// Wrike: [сайт]. [2017]. URL: https://www.wrike.com/ru/blog/shest-razlichnyh-modelej-effektivnosti-komandnoj-raboty/ (дата обращения: 11.11 .2018 )

7. Сорокин А. Компетенции участников проектного управления инновационной деятельностью // Наука и инновации. - 2017. - № 2 (168). - С. 40-43.

8. Дмитриев К., Филимонов А. Стандарты по компетенциям в области управления проектами [электронный ресурс] /Официальный сайт компании Национальной Ассоциации управления проектами СОВНЕТ (дата публикации 10.07.2013)._URL.: http://www.sovnet.ru/library/publications/2792/ (дата обращения: 26.05.2019)

9. МакКлелланд Д. Мотивация человека [Текст] / Д. МакКлелланд.- СПб.: Питер, 2007.-672 с.

10. Армстронг М. Практика управления человеческими ресурсами / М. Армстронг; Пер. с англ. С.К. Мордовин.-СПб.: Питер, 2012.-848 с. 
11. Паркинсон М. Использование психологии в бизнесе: практическое руководство для менеджеров / М. Паркинсон [Пер. с англ.] Серия: Сер. «Бизнес-психология».- М.: НІРРО, 2003 г. - 243 с.

12. Катунина И. В. Конфигурирование офиса управления проектами: опыт инновационной промышленной компании // Стратегические решения и риск-менеджмент.-2018. - № 1 (106). - C. 58-63. https://cyberleninka. ru/article/v/konfigurirovanie-ofisa-upravleniya-proektami-opyt-innovatsionnoy-promyshlennoy-kompanii

13. Дмитриев К., Филимонов А. Стандарты по компетенциям в области управления проектами [электронный ресурс] / Официальный сайт компании Национальной Ассоциации управления проектами СОВНЕТ (дата публикации 10.07.2013).- URL.: http://www.sovnet.ru/library/publications/2792/ (дата обращения 26.05.2019)

14. Дмитриев К., Филимонов А. Стандарты по компетенциям в области управления проектами [электронный ресурс] / Официальный сайт компании Национальной Ассоциации управления проектами СОВНЕТ (дата публикации 10.07.2013). - URL.: http://www.sovnet.ru/library/publications/2792/ (дата обращения 26.05.2019)

15. Cartwright, C. \& Yinger, M. (2007). Project management competency development framework - second edition [электронный ресурс]: PMI ${ }^{\circledR}$ Global Congress 2007-EMEA, Budapest, Hungary. Newtown Square, PA: Project Management Institute.- URL.: https://www.pmi.org/learning/library/project-manager-competencydevelopment-framework-7376 (дата обращения: 26.05.2019)

16. Выход стандарта PMI Project Management Competence Development Framework (РMCDF) - Модель развития компетенций менеджера проекта - второе издание на русском языке [электронный ресурс] / Официальный сайт Московского отделение Project Management Institute: раздел «Новости» (11.06.2013).- URL.: https://pmi.ru/news/1933/ (дата обращения: 26.05.2019)

17. ГОСТ Р 52807-2007. Руководство по оценке компетентности менеджеров проектов. Национальный стандарт РФ.-М.: Стандартинформ, 2010.-18c.

18. ГОСТ Р 53892-2010 Руководство по оценке компетентности менеджеров проектов. Области компетентности и критерии профессионального соответствия. Национальный стандарт РФ.- М.: Стандартинформ, 2011.-20c.

19. A Framework for Performance Based Competency Standards for Global Level 1 and 2 Project Managers [электронный ресурс] / Официальный сайт международного объединения по разработке Стандартов управления проектами Global Alliance for Project Performance Standards (GAPPS).- URL.: https://globalpmstandards.org/ wpcontent/uploads/2014/12/GAPPS_Project_Manager_v1.1150411_A4.pdf (дата обращения: 26.05.2019)

20. Individual Competence Baseline for Project, Programme \& Portfolio Management (ICB). Version 4.0 [Электронный ресурс] / Официальный сайт International Project Management Association: раздел «Products».- URL: http://products.ipma.world/wp-content/uploads/2016/03/IPMA_ICB_4_0_WEB.pdf (дата обращения: 26.05.19).

21. Стандарты по проектной деятельности / Глава из книги Нугайбеков Р. А. Корпоративная система управления проектами: От методологии к практике / Р.А. Нугайбеков, Д.Г. Максин, А.В. Ляшук.- М.: Альпина Паблишер, 2015.-236 с. Цит.по https:/www.cfin.ru/itm/project/standards.shtml

22. Управление проектами: Основы профессиональных знаний, Национальные требования к компетентности специалистов (NCB - SOVNET National Competence Baseline Version 3.0) M.: ЗАО «Проектная ПРАКТИКА», 2010-256 с.

23. ГОСТ Р ИСО 21500-2014 Руководство по проектному менеджменту. Национальный стандарт РФ.- М.: Стандартинформ, 2015.- 52с.

24. Обсуждение профессионального стандарта [электронный ресурс] / Официальный сайт Национальной ассоциации управления проектами «СОВНET» (29.01.2016).- URL.: http://www.sovnet.ru/about/newsblog/3154/?sphrase_id=6477 (дата обращения: 26.05.2019)

25. Руководитель проектов в области информационных технологий. Профессиональный стандарт. Утвержден приказом Министерства труда и социальной защиты РФ от 18.11.2014 № 893н. [электронный ресурс] / Национальный реестр профессиональных стандартов.- URL.: http://profstandart.rosmintrud.ru/obshchiyinformatsionnyy-blok/natsionalnyy-reestr-professionalnykh-standartov/reestr-professionalnykh-standartov/ index.php? ELEMENT_ID=50432 (дата обращения: 26.05.2019)

26. Дмитриев К., Филимонов А. Стандарты по компетенциям в области управления проектами [электронный ресурс] /Официальный сайт компании Национальной Ассоциации управления проектами СОВНЕТ (дата публикации 10.07.2013). - URL.: http://www.sovnet.ru/library/publications/2792/ (дата обращения: 26.05.2019)

27. Сооляттэ, А.Ю. Управление проектами в компании: методология, технологии, практика [Электронный ресурс]: учебник / А.Ю. Сооляттэ.- М.: Московский финансово-промышленный университет «Синергия», 2012.- (Академия бизнеса). Цит. по https:/www.cfin.ru/itm/project/standart_review.shtml 
28. Дмитриев К., Филимонов А. Стандарты по компетенциям в области управления проектами [электронный ресурс] /Официальный сайт компании Национальной Ассоциации управления проектами СОВНЕТ (дата публикации 10.07.2013). - URL.: http://www.sovnet.ru/library/publications/2792/ (дата обращения: 26.05.2019)

29. Клименко О. Создание ключевых компетенций руководителей проектов в компании [электронный ресурс] / Электронная библиотека управления интернет-проекта «Корпоративный менеджмент»: статья из журнала «Финансовый директор».- 2007.- № 9.-URL.: https://www.cfin.ru/management/people/project_competence. shtml (дата обращения: 30.05.2019)

30. Калюжная Н.В. Разработка модели компетенций организации // Молодой ученый. - 2016.- № 6. - C. 447455.-URL https://moluch.ru/archive/110/27084/ (дата обращения: 26.05.2019).

31. Спенсер Л., Спенсер С. Компетенции на работе. Пер. с англ. М.: НІРРО, 2005.- 384 с.

32. Базаров Т. Ю., Ладионенко М.А. Методика создания модели компетентностей // Организационная психология. 2013. № 3, с. 61-77

33. Базаров Т. Ю., Ладионенко М.А. Методика создания модели компетентностей // Организационная психология. 2013. № 3, с. 61-77

34. Компетенции или модели компетенций: есть ли у них будущее? [электронный ресурс] / Официальный сайт компании HighAdvance.- URL.: https:/highadvance.org/our-services/model-kompetencij/kompetencija-jetoopredelenie/ (Дата обращения: 26.05.2018) 